Library Acquisitions: Practice \& Theory, 1992, Vol. 16, Issue 4, p.431-437.

ISSN: 0364-6408

http://www.sciencedirect.com/science/journal/03646408/16

http://www.sciencedirect.com/science/article/pii/036464089290023L

http://dx.doi.org/10.1016/0364-6408(92)90023-L

(C) 1992 Pergamon Press Ltd.

\title{
COLLECTION ASSESSMENT AND ACQUISITIONS BUDGETS: HIGHLIGHTS OF A CONFERENCE
}

\author{
CAROL PITTS HAWKS
}

"Collection Assessment and Acquisitions Budgets" was the theme of the 1992 conference sponsored by the University of Oklahoma Libraries and the University of Oklahoma Foundation held in Oklahoma City, OK, February 20-21. Over 70 participants were greeted by Ron Burton of the University of Oklahoma Foundation and Sul Lee, Dean, University Libraries, University of Oklahoma.

Collection Evaluation and Acquisitions Budgets: A Kaleidoscope in the Making - Charles B. Osburn, Dean, University Libraries, University of Alabama

Osburn opened his presentation with a description of a kaleidoscope, in which motion, change, beauty, color, and control are essential. In comparison, the information universe is growing at unprecedented speed and in new directions electronically. Librarians must take control of this growth and make it an object of beauty.

The interests of everyone - business, industry, society — are becoming more global. Librarians have been called upon to operate simultaneously a traditional library and an electronic one. Librarians have done this by working harder, developing online catalogs, and creating large bibliographic databases. Librarians believe that they are stretched to the limit. Osburn recommended an outward gaze that is more client centered. In addition, a new set of guiding principles must be established. The emphasis must shift from ownership to access and from purchasing for the long-term to providing for expressed needs.

Collection evaluation can be simple or complex. Libraries are experiencing a steady shift from collection-centered approaches to client-centered ones. Two fundamental principles should guide libraries in this area: accountability and setting priorities. It is imperative that libraries solicit information from their clientele. Not only is this a good marketing tool, but it also projects an image of good management.

Materials budgets can be a limiting or enabling factor. As one measure of control it can fund new priorities and directions. Not only does the budget allow libraries to shed the heavy mantle of history, but the budget also becomes the ultimate test of accountability. Libraries will still need to define a core for print collections. Does the concept of a core collection apply to electronic collections as well?

Evaluation has evolved from an ad hoc activity to an embedded responsibility. Collection management decisions increasingly permeate other library functions. 
In Support of Collection Assessment: The Role of Automation in the Acquisitions and Serials Departments - Carol Pitts Hawks, Head, Acquisition Department, The Ohio State University Libraries

Hawks began her presentation by quoting from a presentation at the 1987 Charleston Conference by Joseph Barker. Barker identified three shaping forces in store for most acquisitions librarians in the 13 years leading to the year 2001: the rise of collection management, constraining forces from budgets, and the ramifications and potential of automation. The implications of these changes for the acquisitions department include the continued importance of vendor services, the importance of automation, the call upon acquisitions to be even more accurate and to do even more comprehensive preorder work, and continued efforts to cut staff even further.

In the area of non-traditional opportunities, Hawks addressed the concept of the bibliographer's or scholar's workstation and the use of expert systems in support of collection assessment. In addition to the many "visions" of such products, progress has been made on the development of specific products. Specifically, Hawks described The Bibliographer's Workstation developed by the Southwest Missouri State University Library to facilitate selection of materials by faculty members and librarians. A second system, Selection Advisor, was developed in Australia by Mark Johnston and John Weckert. The system uses six categories of selection criteria in priority order to evaluate each title considered for acquisition: subject, intellectual content, potential use, relation to collection, bibliographic considerations, and language.

Hawks then described a range of products currently available from vendors that can be used in support of collection assessment. The products described include Bowker's BIP Plus, Baker \& Taylor's $B$ \& T LINK, Ebsco's EBSCONET, Faxon's Datalinx, Ebsco's Serials Directory, Bowker's Ulrich's Plus, ABACIS's BookQuest and SerialsQuest, AB Bookman Weekly's Automated Bookman, and OCLC's Collection Analysis CD. In addition, Hawks discussed the role of online review and selection of approval material and automated access to collection development policies and price indices in collection assessment.

In conclusion, a growing number of tools and services are available to facilitate not only the acquisitions process, but to improve our skills and abilities in analyzing collections as they relate to the curriculum and research activities of the institution. Regardless of how proficient librarians become at analyzing, they will always be struggling to anticipate the needs of users.

Serials Cancellation Projects: Necessary Evil or Collection Assessment Opportunity? —Daniel T. Richards, Director of Biomedical Libraries, Dartmouth College

Richards began by posing the question, "Why focus on serials to cancel?" He then identified five reasons: serials represent a permanent financial commitment; they have a higher unit cost and higher increases; payment must be made in advance; cancellation will result in additional savings in the binding and preservation budgets; and serials consume a high percentage of the overall budget. Serials review projects should be seen as an integral part of collection assessment.

Assessment is the process of measuring the degree to which the library actually acquired what it intended to acquire. Assessment is the systematic evaluation of the entire collection development program. Studies are undertaken for a variety of reasons, including to determine preservation priorities, to enhance the skills of the collection manager, to increase understanding of the literature of a particular field, to provide information for accreditation, and to provide information for fund-raising. The primary motivation of reviewing serials is usually a budget crisis. Nevertheless, it is a collection assessment opportunity regardless of what may inspire it. Richards undertook a survey of U.S. health sciences libraries to determine the level of can- 
cellation occurring. As a staff member of NLM at the time, he found that there was concern that health sciences libraries might be becoming too homogenized if they were all cancelling the same titles. In addition, concern was expressed that as a result there would be too much of a drain on the ILL services of the NLM if the trend continued.

The survey revealed that much has been written on doing cancellation projects, but little appears in the literature on the long-term consequences of such projects for scholars. The objectives of the survey were to ascertain the prevalence of cancellation projects, identify the criteria applied, examine the methodology, and determine the level of cancellation decisions for the same titles. The survey group included 125 libraries in U.S. and Canadian medical schools. Ninety-four responses $(75 \%)$ were received. The period surveyed was 1986-1990. The average number of subscriptions in the group was 2,200.

The survey asked ten questions including:

1. Number of titles cancelled,

2. Reasons for cancellation,

3. Who was involved in the decision to cancel,

4. Impact on service,

5. Participation in resource sharing, and

6. Methodology used, such as systematic review of all titles, or review based on one factor such as cost.

The results revealed that the majority of the libraries had been involved in serials review and cancellation. There was a significant variation in the number of titles cancelled per year. 1988 was the peak year with a total of 4,747 titles cancelled. The number of unique titles cancelled over the five-year period totalled 3,341. The average dollar value of all cancellation over five years was $\$ 3.5$ million.

The cancellations fell into four general categories: indexing and abstracting services, foreign language titles, non-medical titles, and interdisciplinary titles. The criteria for cancellation clustered in seven primary areas: low use (69\% of libraries responding), cost (49\%), available from another source (40\%), diminished need (29\%), duplicate subscription (27\%), not indexed in Index Medicus (25\%), and language or geographic origin (23\%). Additional reasons included diminished quality, scope of title changed, ISI impact factor, coverage by another title, and acquisitions difficulties.

The decision to cancel was made in $59 \%$ of the libraries by library staff, the library committee, or library users. The remaining $41 \%$ employed a combination of the three constituencies named above. On the resource sharing front, $67 \%$ of the libraries preferred coordination at the regional or local level, $47 \%$ preferred their current level of participation, and $29 \%$ preferred coordination at the national level.

The impact of these cancellations revealed some expected and unexpected results. Specifically, as expected, $25 \%$ of the libraries felt that the cancellations had no impact, with another $25 \%$ indicating that it was too early to tell the impact. Other predictable results were increased ILL requests, lowered costs, diminished collection quality, and increased user frustration and complaints. Unexpectedly, other libraries felt that the cancellations resulted in improved collection quality and improved user relationships.

The primary methodology employed for serials review projects was systematic review of the entire collection (63\%). Other methodologies include subject-based, review by user groups, 
committee structure, and prioritization of decisions. Five common elements were identified in such projects: statement of goals, general guidelines, criteria to be considered, methodology, and statement of concern.

Me and My Shadow: Vendors as the Third Hand in Collection Evaluation - Dana Alessi, Director, National Academic Sales, Baker \& Taylor Books

Alessi started her presentation with a list of five questions to be addressed.

1. What are the situations where vendors can be helpful?

2. What types of services are offered?

3. How are these products produced?

4. Are these products quantitative or qualitative?

5. How does this library/vendor partnership work?

In answering these questions, Alessi focused on the print products available from vendors.

One vendor-initiated tool is a catalog of titles on a particular theme. Such catalogs include bibliographic information, order forms, and objective annotations. These catalogs are particularly important in the school market and include selections made by librarians, not the vendor's staff. However, it is difficult for the vendor to determine if a particular catalog was the source or cause of an order. Two common misconceptions occur in regard to these catalogs: that titles in the catalog are the only titles in stock or that titles in the catalog are always in stock.

A second tool is bibliographies or lists. These include bibliographic information but no annotations. Common examples include award lists or "hot topics" lists. These lists are meant to be useful but short-lived and do not include any critical judgement.

Vendors often have ongoing tools which can be useful for collection assessment. The first, periodicals such as Baker \& Taylor's Directions include forthcoming titles and annotations. Again, it is difficult for the vendor to determine that such periodicals are the source of orders. The second tool is announcement services, which are usually byproducts of approval plans. These include bibliographic information but no annotations. Such services are only as good as the profile that produces them. Vendors also provide annual reports on their approval plans which are useful for the output and cost statistics they contain.

Alessi next turned to the cost issues and decision factors involved in producing tools useful for collection assessment. First, the marketing department identifies a need for a product. This identification often comes through sales calls, market research, direct customer requests, and competitive products from other vendors. Once a decision to produce a product is made, the vendor must determine the format of that product. Decisions related to producing an ongoing versus a one-time product, its frequency, whether to annotate or not, the expected return of orders versus the expense of the product, and whether to produce a full-fledged publication versus simple advertising must be made.

The editorial department will be expected to identify titles to be included based on the reputation of the author and publisher. They receive input from the buyers and must create the annotations for selected titles. Marketing information such as author tours, book club plans, and print run must be provided. All of the information must be keyed into the vendor's system and coded for the publication in which it will appear. Good creative writing skills are a must at this point. Typesetting software will generate the proofs.

The production department takes the proofs, lays out the pages, works with the printers, 
etc. This is the area of greatest expense so it is usually competitively bid to achieve the best price. The production department is responsible for the quality control function and thus, tries to identify problems at this stage. They oversee the color proofs, instruct the printer and mail house, and maintain the subscription lists even if the publication is gratis. Even for gratis publications, the mailing lists are periodically pruned to hold costs down.

The advertising and sales department sells ads for the publication to decrease the expense. Advertising dollars are becoming more scarce, so this job has become more difficult. Publishers are focusing more on libraries as the most likely prospective purchasers for materials. Advertising is also responsible for the cover art and for working with the ad agency on this project.

It is difficult for the vendor to measure the effectiveness of these general-purpose publications, particularly since they allow the library to order the titles through any source regardless of what mechanism brought the title to their attention. On the other hand, tools that are generated at the request of a particular library are much more likely to result in orders for the specific vendor. These tools (many which were discussed by Hawks) allow librarians to set their own parameters and customize the results. These data are primarily quantitative at this point, but Alessi expects vendors to begin producing qualitative data as well in the near future.

Alessi concluded with a series of questions that libraries working with a particular vendor to define a vendor product should address.

1. What is the library's purpose for the project?

2. How much is the library planning to buy?

3. How much are the collection managers willing to review to make these purchases?

4. What formats and date ranges should be included?

5. In what sequence is the list to be produced?

6. In what review sources from the vendor's database is the library interested?

7. Do you want the books ordered to be shelf ready?

8. Is an interface with an automated system required?

The library and the vendor need to set a reasonable time frame for the data to be extracted and for the library to review and select the material. Orders should be spaced over a period of time.

Collection Assessment and Acquisitions Budgets- Anthony Ferguson, Resources Group Director, Columbia University Libraries

Ferguson opened his presentation with four questions:

1. Why assess?

2. What barriers exist to routine collection assessment?

3. What needs to be done to provide an environment conducive to collection assessment?

4. What are the budget implications?

In addressing the first question, Ferguson indicated that libraries are entering an age of accountability. Institutions are being asked to demonstrate their worth. The revenue base once taken for granted is drying up. Client-centered approaches will emerge as the primary approach. Internal and external competition for resources will increase. Publishers will continue to demand more for less.

Although collection assessment has become more routine than previously, Ferguson 
identified eight barriers. Most bibliographers lack sufficient training to perform collection assessment. There are few meaningful incentives to perform collection assessment. Other responsibilities are too pressing resulting in a lack of time to devote to this activity. Assessment results often do not lead anywhere, particularly if no funds have been set aside to address the deficiencies. Acquisitions, cataloging, and circulation have made strong cases for clerical support. Collection assessment often does not get this clerical assistance. Service is considered of primary importance in most libraries, leaving little time for collection assessment. Assessment activities are currently focused on serials cancellation instead of positive assessment in other areas. Finally, collection management lacks knowledge about the real needs of users, making collection assessment more difficult.

Ferguson espoused several proactive strategies for making the environment conducive to routine collection assessment. Training for collection assessment must be continuous and ongoing. Collection management should have an annual plan that incorporates collection assessment. Separate, designated time for intensive collection assessment should be available, much like research leaves. Funds must be made available to purchase material in the areas under assessment. Efforts must be made to eliminate the artificial division between public services and collection assessment. The information learned in assessment will lead to proactive reference work. Finally, libraries should make the serials crisis an opportunity for positive assessment.

On the budget side, Ferguson believes that libraries cannot afford not to perform collection assessment. However, he acknowledges that time spent on assessment will result in less time spent on other public service duties such as reference desk duty. Thus, managerial overhead will also increase.

Management Data for Selection Decisions in Building Library Collections - Charles Hamaker, Assistant Director for Collection Development, Louisiana State University

Hamaker indicated that thus far in the conference little had been said about the importance of circulation data from online catalogs in collection assessment. Prior to the implementation of online catalogs there were only a very few studies of circulation undertaken. Even today, this is one of the least examined areas as it impacts collection assessment. Hamaker concluded that selection decisions can be informed by meaningful circulation data that answers question such as "Does this book fill a gap?" In the early years of online catalogs, collection management had to compete with many other, more pressing needs for programmer time to write programs to extract the relevant data. At LSU, Hamaker now has a core of programs which can be modified simply and activated.

Hamaker's analysis of data from LSU indicates that the $80 \% / 20 \%$ rule is not valid for their collection. Specifically, $43 \%$ of the physical items in NOTIS circulated at least once in four years. (In-house circulation and reserve room use were excluded from this analysis.)

Hamaker also raised the question of how long this level of circulation can continue before a collection suffers very serious deterioration. His analysis also revealed over 1,000 items that circulated more than 21 times. Of these 1,000+ titles, the heaviest use items were in the HQ classification. These 1,000+ titles were searched in Books in Print resulting in 30\% assumed out of print, but $70 \%$ listed as still in print. These findings suggest that LSU is creating a use collection and not a traditional research collection. 
Locked in Conversation: The College Library Collection and Pluralist Society-Robert Hou-beck, Director of Libraries, University of Michigan-Flint

The thesis of Houbeck's presentation was to determine if academic libraries buy balanced collections. To test this issue, he focused on a study of the major journals on the topic of public opinion including journals divided into liberal and conservative designations. His overall objective was to create a list of titles to test the balance of the collection. He found that liberal titles outnumbered conservative ones two to one. His general strategy was to match each conservative title with an equivalent one on the library side. As a result, 20 titles (10 on each side) were identified as the core for analysis.

Thus refined, his thesis became "Do academic libraries buy more serials on the liberal left than on the conservative right?" Houbeck used the Faxon Datalinx System to identify how many subscriptions Faxon purchased for libraries of these titles in 1991. He speculated that these figures reflected about 1,000 libraries. On the liberal side, 10,874 subscriptions were purchased. On the conservative side, 6,283 subscriptions were purchased. Thus, $73 \%$ more liberal titles were purchased.

Houbeck identified several factors that might explain this outcome. Specifically, inclusion in indexing and abstracting services and the relative age of the publications may work together to result in more liberal title subscriptions. Practically, there are more older liberal titles that are indexed, and/or there are more newer conservative titles that are not indexed. In addition, the recent proliferation of serials cuts and addition of few new titles were possible factors as well.

Annual Survey of Serials Collection Assessment Programs, Practices, and Policies in Academic Libraries, 1991-1992 —Adrian W. Alexander, Regional Manager, The Faxon Company

Due to the unexpected absence of James Smith of The Faxon Company, Adrian Alexander presented a paper prepared jointly by the two authors. Alexander listed again the three shaping forces in store for most acquisitions librarians, as predicted by Joseph Barker in 1987. He presented two hypotheses: that libraries will need more assessment in this new paradigm and that automation will become more important in collection assessment.

A survey on serials collection assessment was developed by Faxon in late 1991 and faxed to test libraries in January 1992. A subjective selection of librarians was made to receive the survey, including heads of acquisitions, heads of serials, and collection development officers. Seven ARL libraries and seven college/university libraries composed the sample for this prototype survey.

The survey asked questions related to the current process for serials budget allocation, increases and decreases in the serials budget for the past three years, the incidence of serials cancellation projects over this three-year period, changes in the ratio of allocation by subject area, current approaches to serials collection assessment, the use of computers in assessment, the use of subscription agency services for assessment, and future plans for collection assessment. The specific survey results will be published in full with the proceedings of this conference in a future issue of the Journal of Library Administration. 